\title{
Solving Bioanalytical Problems by the Method of Matrix-Assisted Laser Desorption/Ionization Mass Spectrometry ${ }^{\dagger}$
}

\author{
Shankai ZhaO ${ }^{\dagger}$, Feng ZHong and Zhihua ZHU \\ Instrumentation Analysis \& Research Center, Zhongshan University, \\ Guangzhou, P. R. China
}

\begin{abstract}
The method of matrix-assisted laser desorption/ionization mass spectrometry has been used to solve some bioanalytical problems, which are difficult to analyze by general methods. For the selection of a proper laser wavelength and matrices, seven matrices were used with laser wavelength of 266 and $355 \mathrm{~nm}$. The results show that with a wavelength of $355 \mathrm{~nm}$ better results could be obtained with most of the matrices. The molecular weight of cytochrome $c$, which was separated by gel electrophoresis and electro-blotted onto nitrocellulose membrane, was determined by matrix-assisted laser desorption/ionization mass spectrometry (MALDI-MS). The accuracy was better than $0.1 \%$, which is much higher than that of sodium dodecyl sulfate-polyacrylamide gel electrophoresis (SDS-PAGE). The three components of protein mixture extracted from crude peanut oil was directly determined by MALDI-MS. The result also demonstrated that these proteins are in a free manner. Since these proteins are in a $2 S$ bond, with the traditional method, SDS-PAGE, it is not possible to decide whether the proteins exist in a combination mode or in a free manner. Water-soluble polymers stained with dyes are used in the technique of two-phase aqueous solution, which is used for separating biomaterials. By using MALDI, the number of the dye molecules that react with the polymer molecules can be determined, which is difficult to determine by other methods.
\end{abstract}

Keywords Matrix-assisted laser desorption, mass spectrometry, protein, molecular weight determination

Since 1988 when Karas and Hillenkamp reported that a protein having a molecular mass greater than 10000 could be analyzed by matrix-assisted laser desorption/ inonization (MALDI) mass spectrometry, different classes of biomolecules, such as proteins ${ }^{1-3}$, polynucleotides $^{4,5}$, oligosaccharides ${ }^{6}$ have been succesfully studied using this technique with a sensitivity in the femtomol range and an accuracy of mass determination of 1 part in $10^{3}$ to $10^{4}$. Since the success of MALDI experiments depends greatly on the choice of the UV-absorbing matrix materials, hundreds of different organic compounds have been chosen, but only few of them work quite satisfactory in most cases. Among those in general use, owing to their different UV absorbance at different laser wavelengths, one must make the correct selection between them. In this paper, experiments for selecting laser wavelengths of $266 \mathrm{~nm}$ and $355 \mathrm{~nm}$ with seven different matrices in the analysis of proteins are performed with a laboratory-built research-grade laser time-of-flight mass spectrometer. The results indicate that a laser wavelength of $355 \mathrm{~nm}$ works better with most of the seven matrices, performing mass spectra with a comparatively lower threshold energy, better re-

\footnotetext{
$\dagger$ Presented at the ASIANALYSIS III, August $20-24,1995$, Seoul, Korea.

\# To whom correspondence should be addressed.
}

producibility and lower low-mass peaks intensity. Three special applications of the method of MALDI in solving bioanalytical problems are described.

\section{Experimental}

\section{Instrumental}

The instrument used in the experiments was a laboratory-built laser time-of-flight mass spectrometer. ${ }^{7}$ For the laser system, a frequency-doubled, -tripled and -quadrupled Nd:YAG laser was used, which provided wavelength of $266,355,553$ and $1064 \mathrm{~nm}$ for selection. The laser beam was focused to a diameter of 10 or 100 $\mathrm{mm}$ with a coaxial viewing system. In the ion-source chamber, a $\pm 20 \mathrm{kV}$ accelerating voltage was applied to the sample holder, and an ion lens was constructed for ion focusing. A gridless two stages reflection mirror installed in the time-of-flight mass analyzer, which worked both in the linear mode and in the reflection mode with resolutions of 650 and 1350 . The drift-length was $1.1 \mathrm{~m}$ in the linear mode and $1.6 \mathrm{~m}$ in the reflection mode. Two sets of ion detectors were set at both sides of the ion mirror. The detectors were constructed with a microchannnel plate placed in front of an electron multiplier, which allowed a gain higher than $10^{7}$. A 40$\mathrm{MHz}$ data-acquisition board plugged in a $486 \mathrm{pc}$ com- 
Table 1 Matrices with their UV absorbance at wavelengths 266 and $355 \mathrm{~nm}$

\begin{tabular}{cccccccc}
\hline & Sinapinic acid & Gentisic acid & Ferulic acid & Pyrazionic acid & $\begin{array}{c}\text { Caffeic } \\
\text { acid }\end{array}$ & $\begin{array}{c}\text { 3-Amino-4- } \\
\text { hydroxybenzoic acid }\end{array}$ & $\begin{array}{c}\text { Nicotinic } \\
\text { acid }\end{array}$ \\
\hline $266 \mathrm{~nm}$ & 3.7569 & 3.3348 & 3.8484 & 3.9726 & 3.9726 & 3.9726 & 3.5480 \\
$355 \mathrm{~nm}$ & 4.3953 & 4.4175 & 4.4175 & 0.4381 & 4.4175 & 4.4175 & 0.0129 \\
\hline
\end{tabular}<smiles>COc1cc(C=CC(=O)O)cc(OC)c1O</smiles>

Sinapinic acid<smiles>O=C(O)C=Cc1ccc(O)c(O)c1</smiles>

Caffeic acid<smiles>O=C(O)c1ccc(O)cc1O</smiles>

Gentisic acid<smiles>Nc1cc(C(=O)O)ccc1O</smiles>

3-Amino-4-hydroxybenzoic acid<smiles>COc1cc(C=CC(=O)O)ccc1O</smiles>

Ferulic acid<smiles>O=C(O)c1cccnc1</smiles>

Nicotinic acid<smiles>O=C(O)c1cnccn1</smiles>

Pyrazionic acid

Fig. 1 Chemical structure of matrices.

puter was used as data-acquisition and -processing system. A sensitivity at the subpicomol level was generally obtained with this instrument.

\section{Sample preparation}

Cytochrome $c$, albumin, sinapinic acid, gentisic acid, ferulic acid, caffeic acid, 3-amino-4-hydroxybenzoic acid, and nicotinic acid were purchased from Sigma Chemical Co. (St. Louis, MO, USA). Pyrazionic acid was purchased from Tokyo Kasei Co., Japan. The extracted protein mixture from the crude peanut oil, and the polymer PEG 6000 and the red dye were given by Dr. Zhou, Department of Biochemistry. Samples were dissolved in $0.1 \%$ aqueous trifluoroacetic acid (TFA) with $10^{-4} \mathrm{M}$ concentration. Solid matrix materials were dissolved in a 1:1 mixture of acetonitrile+water with a $0.1 \mathrm{M}$ concentration. After $5 \mu \mathrm{l}$ of a sample solution was mixed with $5 \mu$ l of the matrix solution, $2 \mu$ l of the mixture was dripped onto a silver target, or membrane, and dried in air before insertion into the ion-source chamber.

\section{Results and Discussion}

For selecting the laser wavelength between $266 \mathrm{~nm}$ and $355 \mathrm{~nm}$, seven matrices were used for determining cytrochrome $c(\mathrm{mw}=12360)$ and albumin $(\mathrm{mw}=66000)$. Table 1 lists seven matrices with their UV absorbance at wavelengths of 266 and $355 \mathrm{~nm}$. Figure 1 gives their chemical structures. The results demonstrated that a wavelength of $355 \mathrm{~nm}$ works better with most of the matrices, except that with nicotinic acid and 3-amino-4hydroxybezoic acid. Nicotinic acid works well at a wavelength of $266 \mathrm{~nm}$, and 3-amino-4-hydroxybenzoic acid even cannot perform molecular ions in the mass spectrum with both 266 and $355 \mathrm{~nm}$. A detail discussion of the results will be presented in another paper. In the following experiments, sinapinic acid was used as a matrix with a laser wavelength of $355 \mathrm{~nm}$.

Gel electrophoresis is a widely used method for separating biomaterials, and SDS-PAGE is a traditional method applied for determining molecular weight of a subunit of proteins and peptides. It suffers due to its relatively low accuracy $(5-10 \%)$. We used cytochrome $c$ as an example run in a normal SDS-PAGE experiment, and then electroblotted it onto a nitrocellulose (NC) or a nylon membrane. Then, the NC or nylon membrane was cut into a small piece having an area of about three square $\mathrm{mm}$, and placed onto the sample holder by double-sided sticky tape. A $5 \mu \mathrm{l}$ matrix solution was dripped onto the membrane, and then dried in air before insertion into the ion-source chamber. By the MALDI method, the molecular weight of cytochrome $c$ was accurately determined (better than $0.1 \%$ ).

The nylon membrane gave a better result than the NC membrane did. The results is shown in Fig. 2a, b. The molecular ion peak shown in the spectrum is broader than that taken with a pure cytochrome $c$ sample. This is due to the contamination from the buffer solutions added during gel electrophoreses. However, measuring the peak centroid, accurate results were obtained. 

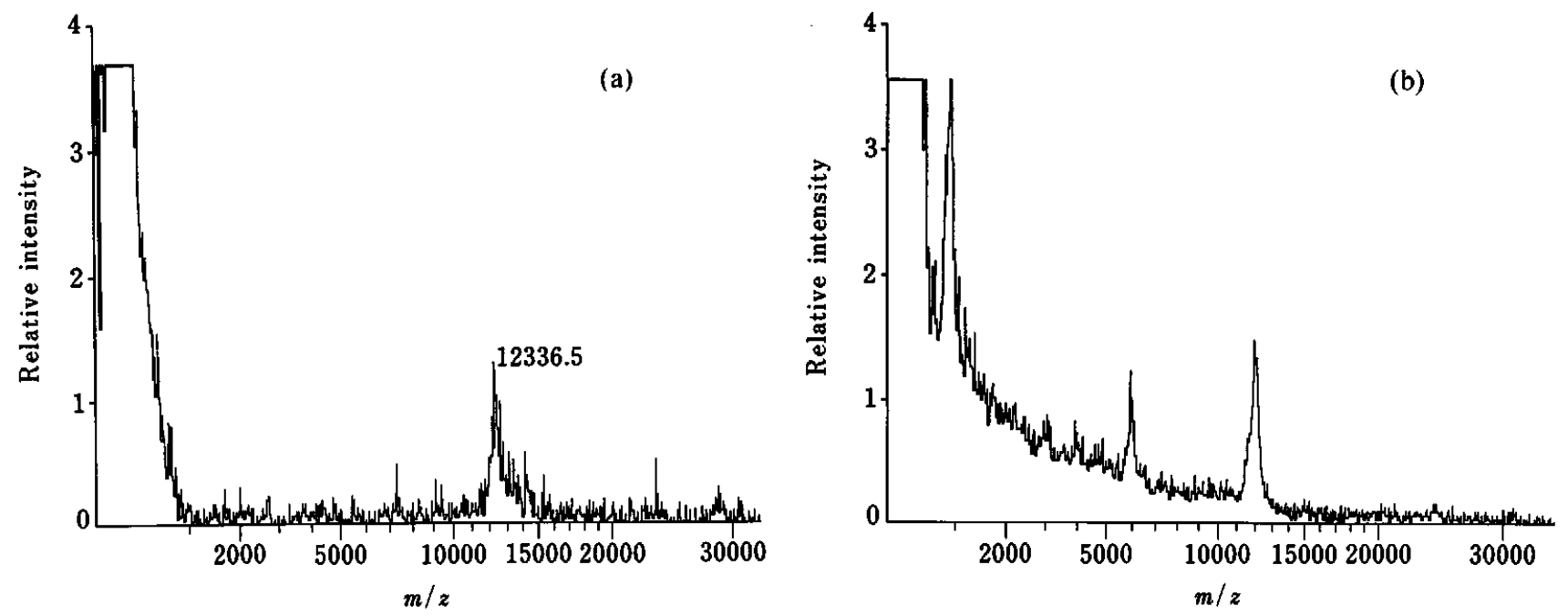

Fig. 2 MALDI spectrum of cytochrome $c$ seperated by SDS-PAGE and electroblotted onto (a) nylon membrane and (b) NC membrane.

A protein mixture extracted from crude peanut oil was separated and determined by SDS-PAGE. Three proteins were separated, and their molecular weights measured $(14000,15000$ and 17000$)$. Since these proteins had the $2 \mathrm{~S}$ bond structure, by the method of SDSPAGE we were not able to determine whether the proteins existed in a combination mode or in a free manner. However, by the the MALDI method, we could directly determine the molecular weight of these three components of extracted protein mixture without any further purification $(13993,15723$ and 17037). The results also indicated that the proteins existed in the free manner, and not in the combination mode. The spectrum is shown in Fig. 3. The comparatively broad molecular ion peaks were due to the impurities in the sample, because it was not purified. However, the molecular-ion peaks of the three components observed as well as their double-charged and dimmer-ion peaks were clearly observed.

The technique of two-phase aqueous solution is an effective method for separating biomaterials. Watersoluble polymers stained with a dye are used in this

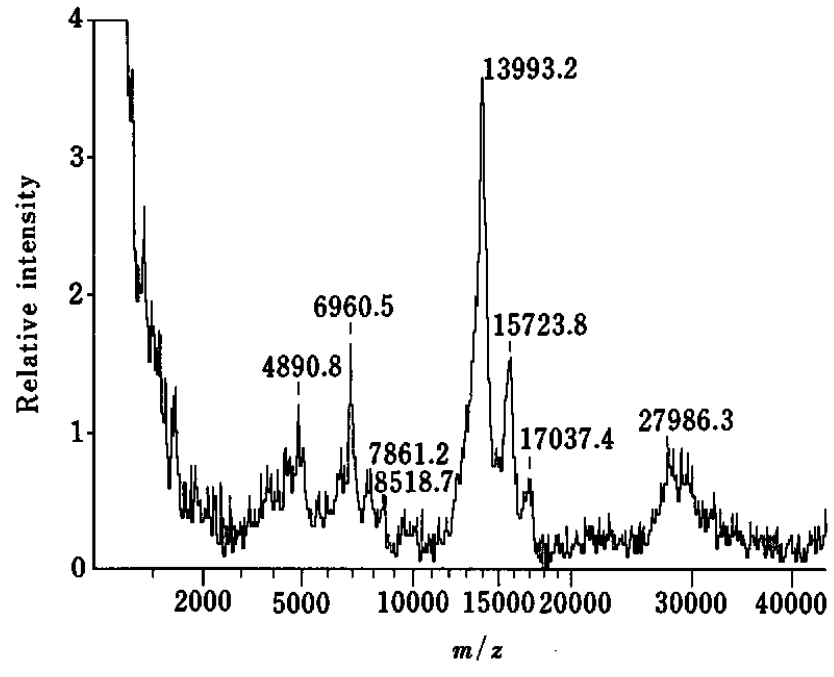

Fig. 3 MALDI spectrum of proteins mixture extracted from peanut oil.
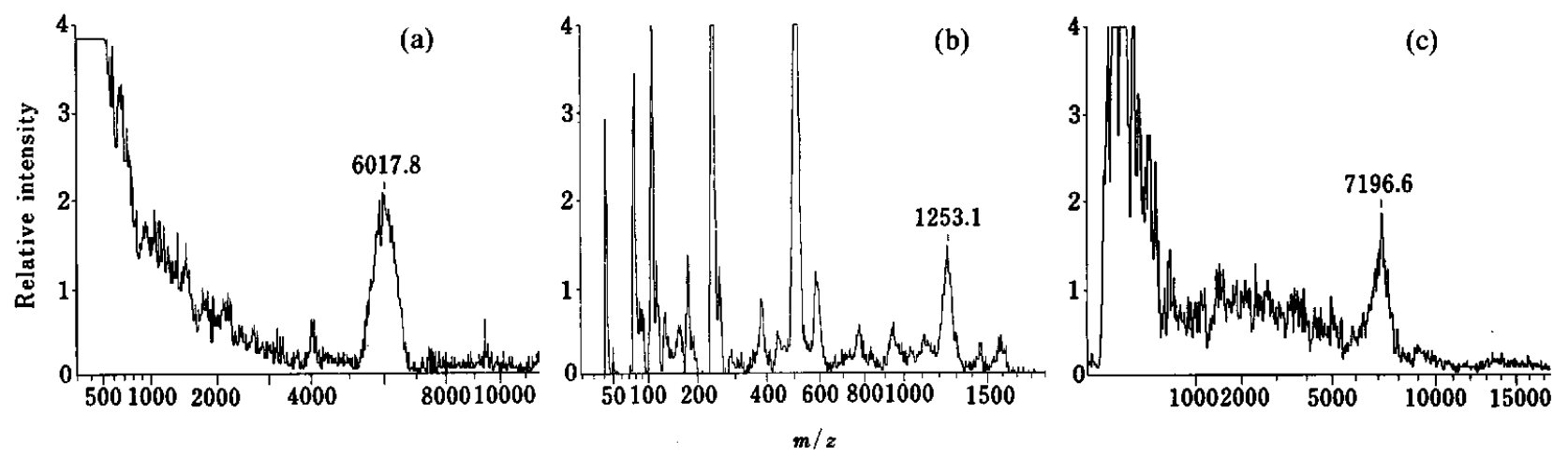

Fig. 4 MALDI spectra of (a) PEG 6000, (b) red dye and (c) PEG 6000 and red-dye-reacted compound. 
technique. One wants to know: are the polymers combined with the dye molecule, and how many dye molecules does it combine? MALDI answers these questions quite well. Using the MALDI method, we can directly determine the molecular weight of PEG polymers, the red dye and their reaction product. The results are shown in Figs. $4 a, b$ and $c$. As can be observed from the spectra, the molecular weight of the red dye molecule is 1253 and the mass-average molecular weight of PEG 6000 is 6017 . The mass measured in the spectrum of their reaction product is 7196 . The results apparently demonstrated that one molecule of red dye combines with PEG polymer molecules.

\section{References}

1. M. Karas and F. Hillenkamp, Anal. Chem., 60, 2299
(1988).

2. R. C. Beavis and B. T. Chait, Rapid Commum. Mass Spectrom., 3, 432 (1989).

3. S. Zhao, K. V. Samayajula, A. G. Sharkey, D. M. Hercules, F. Hillenkamp, M. Karas and A. Ingendoh, Anal. Chem., 63, 450 (1991).

4. K. Tang, S. L. Allmen, C. H. Chen, L. Y. Chang and M. Sohell, Rapid Commun. Mass Spectrom., 8, 183 (1993).

5. E. Norhaff, A. Ingendoh, R. Cramer, A. Overberg, B. Stahl, M. Karas, F. Hillenkamp and B. Crain, Rapid Commun. Mass Spectrom., 6, 771 (1993).

6. M. Karas, A. Ingendolf and F. Hillenkamp, Anal. Chem., 63, 2470 (1991).

7. S. Zhao, F. Zhong, Q. Zha and D. Chen, Fenxi Huaxue, 22, 1079 (1994).

(Received October 11, 1995)

(Accepted February 14, 1996) 